\title{
Anoctamin 1 is Apically Expressed on Thyroid Follicular Cells and Contributes to ATP- and Calcium-Activated Iodide Efflux
}

\author{
Carmela Iosco ${ }^{a}$ Cristina Cosentino ${ }^{a}$ Laura Sirna $^{\mathrm{a}}$ Roberta Romano \\ Silvia Cursano Alessandra Mongia ${ }^{a}$ Giampaolo Pompeo ${ }^{a}$ Julie di Bernardoa \\ Claudio Ceccarellib Giovanni Tallinic Kerry J. Rhoden ${ }^{\mathrm{a}, \mathrm{d}}$
}

\begin{abstract}
aMedical Genetics Unit, Department of Medical and Surgical Sciences (DIMEC), University of Bologna, ${ }^{b}$ Anatomic Pathology Unit, S. Orsola-Malpighi Hospital, Department of Experimental, Diagnostic and Specialty Medicine (DIMES), University of Bologna, 'Anatomic Pathology Unit, Bellaria Hospital, Department of Experimental, Diagnostic and Specialty Medicine (DIMES), University of Bologna, dinterdepartmental Center for Industrial Research - Health Sciences and Technologies (CIRI-SdV), University of Bologna, Bologna, Italy
\end{abstract}

\section{Key Words}

Thyroid gland $•$ Iodide $\cdot$ Ion channel $\cdot$ Anoctamin $•$ ANO1 $\cdot$ TMEM16A

\begin{abstract}
Background/Aims: Iodide efflux from thyroid cells into the follicular lumen is essential for the synthesis of thyroid hormones, however, the pathways mediating this transport have only been partially identified. A calcium-activated pathway of iodide efflux has long been recognized, but its molecular identity unknown. Anoctamin 1 (ANO1) is a calcium-activated chloride channel ( $\mathrm{CaCC})$, and this study aims to investigate its contribution to iodide fluxes in thyroid cells. Methods: RT-PCR, immunohistochemistry, and live cell imaging with the fluorescent halide biosensor YFP-H148Q/I152L were used to study the expression, localization and function of ANO1 in thyroid cells. Results: ANO1 mRNA was detected in human thyroid tissue and FRTL5 thyrocytes, and ANO1 protein was localized to the apical membrane of follicular cells. ATP induced a transient loss of iodide from FRTL-5 cells that was dependent on the mobilization of intracellular calcium, and was inhibited by CaCC/ANO1 inhibitors and siRNA against ANO1. Calcium-activated iodide efflux was also observed in $\mathrm{CHO}$ cells over-expressing the Sodium Iodide Symporter (NIS) and ANO1. Conclusion: ANO1 in thyrocytes functions as a calciumactivated channel mediating iodide efflux, and may contribute to the rapid delivery of iodide into the follicular lumen for the synthesis of thyroid hormones following activation by calciummobilizing stimuli.
\end{abstract}

Copyright (c) 2014 S. Karger AG, Basel

Kerry J. Rhoden

U.O. Genetica Medica, Policlinico S. Orsola-Malpighi pad 11,

via Massarenti 11, Bologna 40138 (Italy)

Tel. +39-051-2088412, Fax +39-051- 2088416, E-Mail kerry.rhoden@unibo.it 


\section{Introduction}

The thyroid gland accumulates iodide for the synthesis of thyroid hormones. Circulating iodide is actively concentrated in thyroid follicular cells by the Sodium Iodide Symporter (NIS) or SLC5A5, a cotransporter located on the basolateral membrane that uses the inward $\mathrm{Na}^{+}$ gradient generated by the $\mathrm{Na}^{+}-\mathrm{K}^{+}$ATPase to drive iodide uptake against its electrochemical gradient [1]. Intracellular iodide then passively diffuses across the apical membrane into the follicular lumen where it is incorporated into thyroglobulin in a reaction catalyzed by thyroid peroxidase. Whereas there is a consensus that basolateral iodide uptake is uniquely mediated by NIS, multiple anion channels and/or transporters are thought to contribute to the delivery of intracellular iodide to the follicular lumen. These pathways may be differentially regulated according to the physiological needs for thyroid hormone synthesis. Indeed, radioiodide efflux from thyroid cells has been shown to be stimulated by G proteincoupled receptors activating distinct signaling pathways, including calcium-, PKC-, PLA ${ }_{2}^{-}$, and cAMP-dependent mechanisms [2-9].

The pathways mediating apical iodide efflux from thyroid cells are still largely unknown. The major candidate is pendrin or SLC26A4, first identified as the protein mutated in Pendred syndrome, an inherited disorder associated with deafness, goiter and impaired iodide organification [10]. Pendrin is located on the apical membrane of thyroid follicular cells, supports $\mathrm{Cl}^{-} / \mathrm{I}^{-}$exchange, and mediates iodide efflux from polarized cells with heterologous expression of NIS and pendrin [11-13]. However, pendrin-knockout mice are euthyroid, and not all subjects bearing homozygous loss-of-function mutations manifest thyroid dysfunction, suggesting redundancy in the role of pendrin in the thyroid gland [14, 15].

Thyrocytes express several chloride channels known to be permeable to iodide, and it has been proposed that such channels may also contribute to iodide efflux. The cystic fibrosis transmembrane conductance regulator (CFTR) is expressed in the thyroid gland [16] and subclinical hypothyroidism has been reported in cystic fibrosis patients [17]. CFTR is active as a regulated apical chloride conductance in the pig thyroid [18], but its role in iodide fluxes has not yet been investigated. Nevertheless, several models have been proposed by which CFTR may modulate thyroid iodide fluxes. Thus, CFTR may directly transport iodide, may supply chloride as the counterion for pendrin-dependent $\mathrm{Cl}^{-} / \mathrm{I}^{-}$exchange, or may alter sodium fluxes and by consequence NIS-mediated iodide uptake [18].

The voltage-gated CIC-5 chloride channel is highly expressed in the thyroid gland of mice and is localized to the apical pole of thyrocytes [19]. CLC-5 knockout mice develop euthyroid goiter and have delayed iodide organification compatible with impaired delivery of iodide to the follicular lumen [19]. However, pendrin expression is also reduced in CLC-5 deficient mice, suggesting that delayed iodide efflux may be secondary to pendrin downregulation [19].

Anoctamin 1 (ANO1, TMEM16A) is a calcium-activated chloride channel (CaCC) with a role in transepithelial electrolyte transport, nociception, and smooth muscle contractility [20-23]. It belongs to a widely-distributed anoctamin family of 10 paralogs (ANO1-10; TMEM16A-K) sharing a common transmembrane topology, but differing in function, which for many anoctamins is still unknown $[23,24]$. AN01 mRNA is present in the thyroid gland [25-27], and CaCC currents have been recorded in thyroid follicular cells, where they have been proposed to play a role in regulating in chloride and iodide homeostasis [27, 28]. ANO1 has a higher permeability for iodide than for chloride $[21,22]$ raising the possibility that thyroidal ANO1 may function as a calcium-activated iodide channel contributing to the delivery of iodide to the follicular lumen. Several agents have been reported to stimulate calcium-dependent radioiodide efflux from cultured thyrocytes [2-5, 8], however, the channel or transporter mediating this response has yet to be elucidated. This study was designed to examine the expression and localization of ANO1 in the thyroid gland, and test the hypothesis that ANO1 mediates calcium-activated iodide efflux from thyroid follicular cells. 


\section{Materials and Methods}

Immunohistochemistry

Excess non-neoplastic thyroid tissue was obtained, after histologic review, from the Anatomic Pathology archives of the Bellaria Hospital (Bologna, Italy). Formalin-fixed tissue sections were dewaxed, rehydrated, and subjected to antigen retrieval (Tris-EDTA pH 9.0, $98^{\circ} \mathrm{C}, 20 \mathrm{~min}$ ). Endogenous peroxidase activity was blocked with methanol (0.5\%, $20 \mathrm{~min}$ ). Sections were incubated overnight with rabbit monoclonal antibody against ANO1 (clone SP31, Spring Bioscience, Pleasanton, CA, USA) [29], and processed with the Novolink Polymer detection system (Novocastra, UK) according to the manufacturer's instructions. Negative control tissue sections were processed in parallel by omitting the primary antibody.

\section{Cell culture, cDNA transfection and siRNA treatment}

FRTL-5 rat thyroid follicular cells were cultured in Coon's Modified F12 medium supplemented with $5 \%$ newborn calf serum, $1 \mu \mathrm{g} / \mathrm{ml}$ insulin, $3.6 \mathrm{ng} / \mathrm{ml}$ hydrocortisone, $5 \mu \mathrm{g} / \mathrm{ml}$ apotransferrin, $10 \mathrm{ng} / \mathrm{ml}$ glycyl-L-histidyl-L-lysine acetate, $10 \mathrm{ng} / \mathrm{ml}$ somatostatin and $1 \mathrm{mU} / \mathrm{ml} \mathrm{TSH}, 100 \mathrm{U} / \mathrm{ml}$ penicillin, and 100 $\mu \mathrm{g} / \mathrm{ml}$ streptomycin [30]. A cell line with stable expression of the iodide-sensitive yellow fluorescent protein YFP-H148Q/I152L (FRTL-5/YFP) was used to monitor iodide fluxes [31]. ANO1 gene silencing in FRTL-5/ YFP cells was carried out with siRNA directed against rat AN01. Pre-designed Mission siRNA (100 nM) against rat AN01 (RefSeq ID NM_001107564) or a scrambled negative control were transfected using N-TER nanoparticles according to manufacturer's instructions (Sigma-Aldrich). Cells were used 48-72 h later for mRNA analysis or measurement of iodide fluxes.

CHO (Chinese hamster ovary) cells were cultured in F12 medium supplemented with 10\% fetal bovine serum, $100 \mathrm{U} / \mathrm{ml}$ penicillin and $100 \mu \mathrm{g} / \mathrm{ml}$ streptomycin. A CHO cell line with stable expression of YFPH148Q/I152L and NIS (designated CHO/YFP/NIS) was established by transfection with Lipofectamine 2000 (Life Technologies Italia, Monza, Italy) and selection with appropriate antibiotics. First, CHO cells were transfected with a pcDNA3-Neo vector containing the YFP-H148Q/I152L coding sequence and cultured in the presence of $400 \mu \mathrm{g} / \mathrm{ml}$ geneticin. Cell lines with persistent and uniform fluorescence were then transfected with pcDNA3.1/Zeo containing the full length human NIS cDNA (S. Jhiang, Ohio State University), and selected with $250 \mu \mathrm{g} / \mathrm{ml}$ zeocin. Cell lines were screened for NIS-mediated iodide uptake using the YFPbased fluorescence assay, as previously described [31]. ANO1 was transiently expressed in CHO/YFP/NIS cells by transfection with pcDNA 3.1 containing cDNA for human ANO1 $a b c$ isoform (LJV Galietta, Genova, Italy) using Lipofectamine. Mock transfection with empty vector was used as a negative control. 48-72 h later cells were used for mRNA analysis or iodide flux measurement.

mRNA analysis

Total RNA was extracted from thyroid cells or frozen thyroid tissue using TRIzol (Life Technologies Italia, Monza, Italy) and treated with DNase I to remove genomic DNA. First-strand cDNA was synthesized with a Taqman Reverse Transcription Reagent kit (Life Technologies, Monza, Italy) using random hexamers and Multiscribe Reverse Transcriptase. Samples without reverse transcriptase were processed in parallel as negative controls. For standard RT-PCR, cDNA amplification was carried out with the TaqMan PCR Core Reagent Kit using AmpliTaq Gold DNA polymerase (Life Technologies Italia, Monza, Italy). PCR was performed in a Veriti Thermal Cycler (Applied Biosystems) with the following steps: uracil-N-glycosylase (UNG) treatment at $50^{\circ} \mathrm{C}$ for $2 \mathrm{~min}$; UNG inactivation and DNA denaturation at $95^{\circ} \mathrm{C}$ for $10 \mathrm{~min}$; 35 cycles of $95^{\circ} \mathrm{C}$ for $15 \mathrm{sec}, 60^{\circ} \mathrm{C}$ for $30 \mathrm{sec}$ and $72^{\circ} \mathrm{C}$ for $30 \mathrm{sec}$; final elongation at $72^{\circ} \mathrm{C}$ for $7 \mathrm{~min}$. Quantitative RT-PCR was carried out on a 7500 Fast Real-time PCR System using SYBR Green Master Mix (Life Technologies Italia, Monza, Italy) with the following steps: denaturation at $95^{\circ} \mathrm{C}$ for $20 \mathrm{sec}$, followed by 40 cycles of $95^{\circ} \mathrm{C}$ for 3 sec and $60^{\circ} \mathrm{C}$ for $30 \mathrm{sec}$. Primer sequences were selected from published sources [32] or designed using Primer-BLAST, and are available on request. When rat sequences were not available in Refseq, primers were designed against mouse or predicted rat transcripts. Target gene expression was normalized against $\beta$-actin as a reference gene, and expressed as $2^{-\Delta \Delta C t}$. The amplification efficiency of target and reference genes was equal and close to 1 .

YFP-based iodide flux assay

Iodide fluxes were monitored as iodide-induced changes in fluorescence in cells expressing YFP-H148/ I152L, as described previously [31]. Cells were cultured on glass coverslips, mounted in a thermostatically- 
Iosco et al.: Anoctamin 1 in the Thyroid Gland

controlled imaging chamber (Warner Instruments, Hamden, CT, USA), and perfused at $37^{\circ} \mathrm{C}$ with a phosphatebuffered balanced salt solution (BSS) composed of $137 \mathrm{mM} \mathrm{NaCl}, 2.7 \mathrm{mM} \mathrm{KCl}, 0.7 \mathrm{mM} \mathrm{CaCl}{ }_{2}, 1.1 \mathrm{mM} \mathrm{MgCl}_{2}$, $1.5 \mathrm{mM} \mathrm{KH}_{2} \mathrm{PO} 4,8.1 \mathrm{mM} \mathrm{Na}_{2} \mathrm{HPO} 4$ and $10 \mathrm{mM}$ glucose (pH 7.4). BSS containing $100 \mathrm{mM} \mathrm{I}^{-}$was prepared by

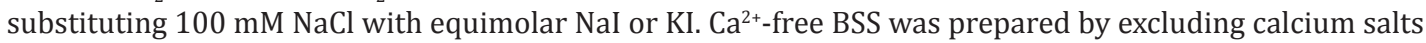
and adding 2 mM EGTA. Chloride-free BSS was prepared by substituting chloride salts with glutamate salts.

Fluorescence (excitation $500 \pm 12.5 \mathrm{~nm}$, emission $545 \pm 17.5 \mathrm{~nm}$ ) was monitored with an Axiovert 200 inverted microscope using a 40x objective (Carl Zeiss, Arese, Italy). Images were acquired for $50 \mathrm{~ms}$ every 2s with a Photometrics Coolsnap fx CCD camera (Crisel Instruments, Rome Italy). Fluorescence intensity was quantified with Universal Imaging Metafluor software (Crisel Instruments, Rome, Italy). Cellular fluorescence was monitored as the average intensity of a population of cells (typically 20-100), or of individual cells within a population, after subtraction of background fluorescence. In order to correct for fluorescence decay due to photobleaching, resting fluorescence of cells perfused with BSS was fit over time to a 1-phase exponential decay function, to obtain a best fit curve $\left(\mathrm{F}_{0}\right)$. Fluorescence at each time point (F) during the experiment was normalized to $\mathrm{F}_{0}$, and relative fluorescence $\left(\mathrm{F} / \mathrm{F}_{0}\right)$ was expressed as a $\%$ value. Iodide influx was expressed as the maximal rate of fluorescence quenching $\left(\% \mathrm{~s}^{-1}\right)$, determined by fitting $\mathrm{F}$ / $\mathrm{F}_{0}$ data to a 1- or 2-phase exponential decay curve and obtaining the derivative of the best-fit curve at the point of maximal slope. Iodide efflux was expressed as the maximal rate of fluorescence recovery $\left(\% \mathrm{~s}^{-1}\right)$, where $0 \%$ recovery refers to the fluorescence of iodide-loaded cells, and $100 \%$ is the resting fluorescence of cells lacking iodide. ATP $\mathrm{EC}_{50}$ and Hill coefficients were obtained by non-linear regression fitting of log concentration-response replicate data to a sigmoidal curve. Fluorescence data analysis and curve fitting was carried out with GraphPad Prism (GraphPad Software, La Jolla, CA, USA).

\section{Statistical analysis}

Statistical analysis was carried out with GraphPad Prism. Data are expressed as mean values_SEM of $\mathrm{n}$ values, where $\mathrm{n}$ represents the number of independent experiments, or when specifically indicated, the number of single cells analyzed. Comparisons between treatment groups were made by one-way ANOVA followed by Dunnett's or Bonferroni's multiple comparison test. Statistical significance was assumed for $\mathrm{p}<0.05$.

\section{Results}

\section{Anoctamin expression in thyroid tissue and cells}

Immunohistochemistry of normal human thyroid tissue with an antibody against ANO1, routinely used to support a pathologic diagnosis of GIST [29], revealed positive staining on follicular cells (Fig. 1A). Staining was less intense than in GIST samples, despite the use of a more concentrated antibody (1:300 versus 1:400). Staining was always restricted to the apical membrane of thyrocytes, facing the lumen of thyroid follicles. Staining of follicles within the same tissue section was of variable intensity, but was more evident in follicles with columnar cells rather than low cuboidal cells, suggesting a greater expression of ANO1 in activated cells than in quiescent cells. No staining was seen in parafollicular C-cells. Staining was absent from thyroid and GIST tissue sections processed in parallel without primary antibody.

AN01 mRNA was detected in human thyroid tissue (Fig. 1B), as well as in rat FRTL-5 thyroid cells (Fig. 1C). FRTL-5 cells also expressed mRNA for other anoctamins, specifically ANO6, ANO8 and ANO10 (Fig. 1C). Cells cultured without TSH for 7 days retained ANO1 mRNA expression (Fig. 1D); in contrast, NIS mRNA was eliminated, consistent with the known dependence of NIS expression on TSH [1].

Alternative splicing of ANO1 transcripts is known to produce several isoforms, some of which differ in their functional properties [25]. Isoforms lacking certain protein segments are generated by use of an alternative promoter (segment $a$ ), or skipping of exon $6 \mathrm{~b}$ (segment $b$ ), exon 13 (segment $c$ ) and exon 15 (segment $d$ ). RT-PCR analysis of ANO1 splice variants in FRTL- 5 cells showed that segments $a$ and $c$ are present in all transcripts whereas segment $d$ is always skipped (Fig. 1E). In contrast, dual bands corresponding to transcripts with and 


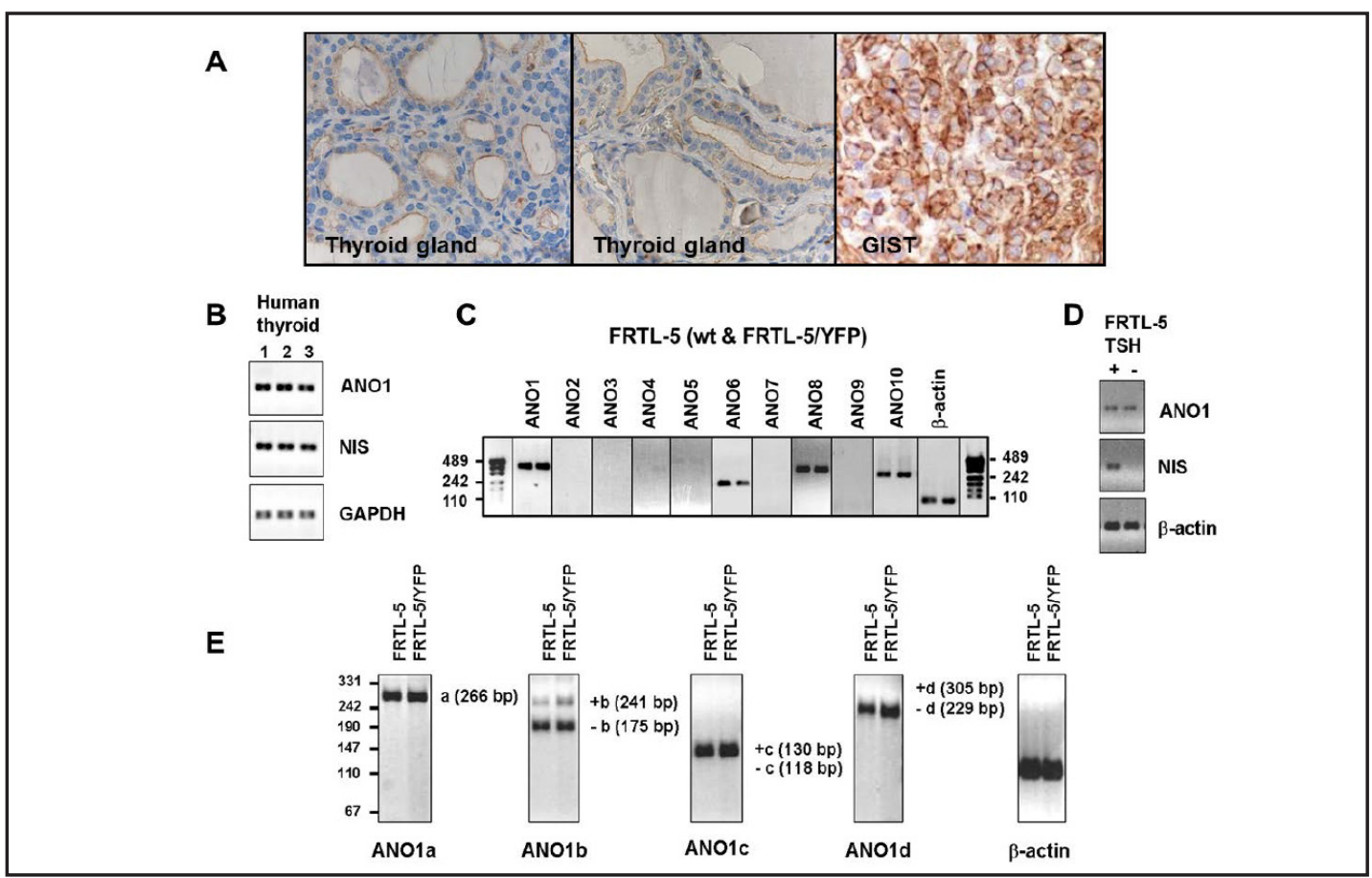

Fig. 1. Anoctamin expression in the thyroid gland. (A) ANO1 immunoreactivity in the human thyroid gland ( 2 independent samples); reactivity is restricted to the apical surface of follicular cells and is more evident in follicles with columnar rather than cuboidal cells. A GIST sample is shown as a positive control. (B-E) RT-PCR analysis and visualization of amplification products on $2 \%$ agarose gels stained with ethidium bromide. (B) ANO1 and NIS amplicons from three independent samples of human thyroid tissue. (C) Anoctamin family members in FRTL-5 thyrocytes; two lanes for each anoctamin correspond to wild-type FRTL-5 cells (left lane) and FRTL-5/YFP cells (right lane). (D) Effect of TSH withdrawal (7 days) on ANO1 and NIS mRNA expression in FRTL-5 thyrocytes. (E) ANO1 splice variants in FRTL-5 thyrocytes corresponding to the inclusion or exclusion of protein segments $a, b, c$, and $d$. Primers for segment $a$ reveal a single band when the segment is present, but no band when absent; primers for segments $b$ - $d$ produce two bands corresponding to the presence or absence of segments. For all RT-PCR analyses shown, bands correspond to the expected product size, and reactions without reverse-transcriptase were negative.

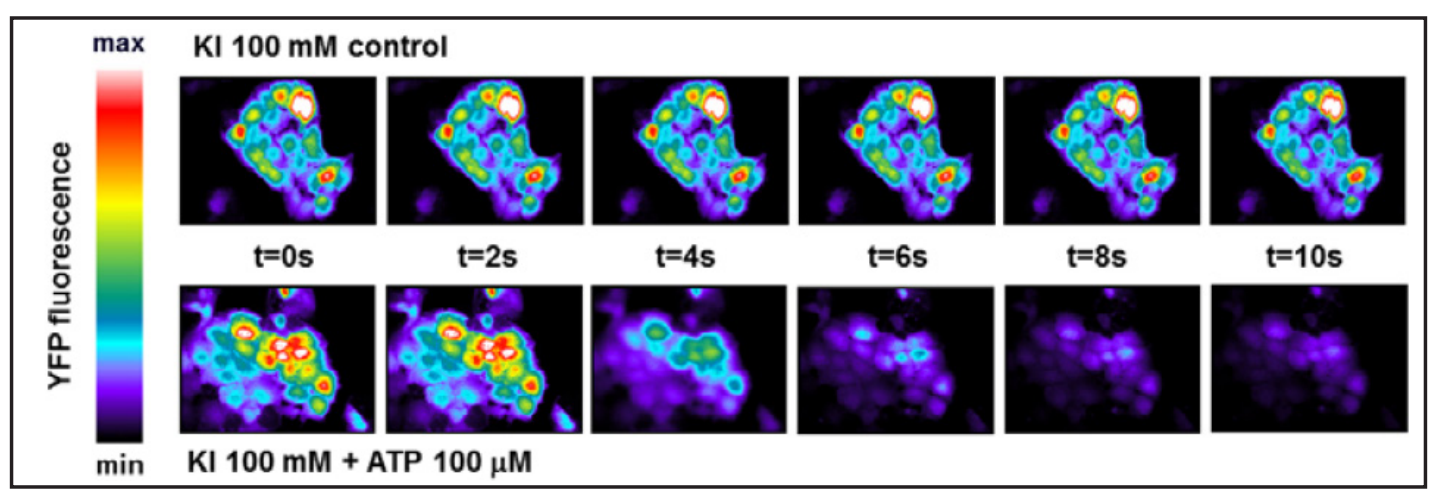

Fig. 2. Stimulation of CaCC activity in FRTL-5/YFP cells by ATP. Pseudocolor images of fluorescence intensity, showing time-dependent quenching due to iodide influx following substitution of $100 \mathrm{mM} \mathrm{NaCl}$ with equimolar KI in the absence (top panel) or presence of $100 \mu \mathrm{M}$ ATP (lower panel).

without segment $b$ were detected. These results suggest that FRTL- 5 cells express ( $a b c)$ and (ac) isoforms. FRTL-5/YFP cells, used for iodide flux measurements, expressed a similar pattern of anoctamins and AN01 isoforms as wild-type FRTL-5 cells (Fig. 1E). 

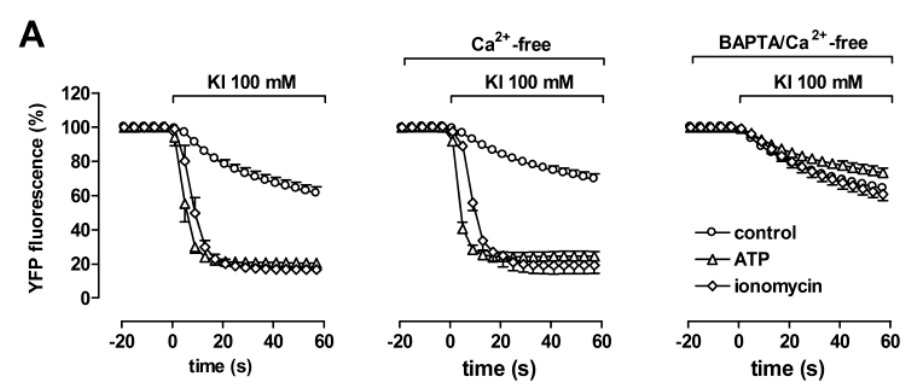

\section{B}

C
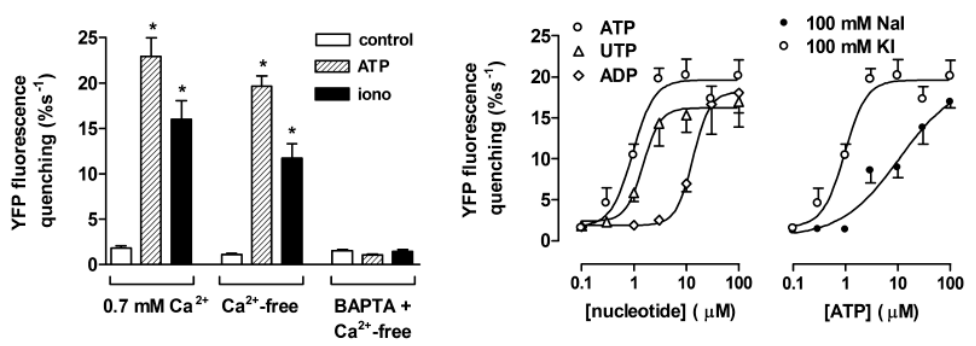

D

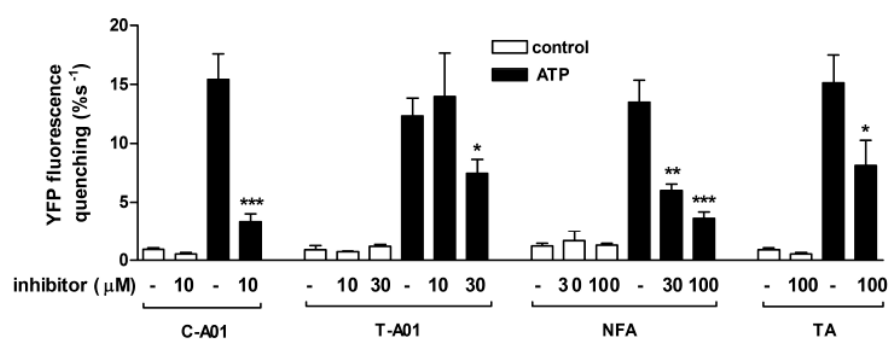

Fig. 3. Purinergic stimulation of CaCC activity in FRTL-5/YFP cells. Unless otherwise specified fluorescence quenching was induced by substituting $100 \mathrm{mM} \mathrm{NaCl}$ with equimolar $\mathrm{KI}$, and $\mathrm{CaCC}$ activity was induced with $100 \mathrm{uM}$ ATP or $1 \mathrm{uM}$ ionomycin (iono). (A) Time course of ATP- and ionomycin-stimulated fluorescence quenching in the presence of $0.7 \mathrm{mM} \mathrm{Ca}^{2+}$ (left panel), $\mathrm{Ca}^{2+}$-free medium (central panel), and $\mathrm{Ca}^{2+}$-free medium in cells pre-treated with $10 \mu \mathrm{M}$ BAPTA-AM for $45 \mathrm{~min}$ (right panel). (B) Calcium-dependence of CaCC activity, expressed as the maximal rate of fluorescence quenching derived from time course data in (A). * $\mathrm{p}<0.001$ vs. control. (C) P2Y receptor stimulation of CaCC activity (left), and effect of substituting $100 \mathrm{mM}$ $\mathrm{NaCl}$ with equimolar KI or NaI on ATP potency (right). (D) Effect of AN01/CaCC inhibitors T16Ainh-A01 (T-A01), CaCCinh-A01 (C-A01), niflumic acid (NFA) and tannic acid (TA) on ATP-stimulated CaCC activity, expressed as the maximal rate of iodide-induced fluorescence quenching. ${ }^{*} \mathrm{p}<0.05,{ }^{* *} \mathrm{p}<0.01$ vs ATP, no inhibitor. In all panels, points or bars represent mean+SEM of 4-9 independent experiments.

\section{CaCC activity in FRTL-5 cells}

To determine whether thyroid cells possess CaCC activity compatible with ANO1, anion fluxes were measured in FRTL-5/YFP cells cultured without TSH for 7-10 days in order to eliminate NIS-mediated iodide uptake. CaCC activity was measured by substituting 100 $\mathrm{mM} \mathrm{NaCl}$ in the perfusate with equimolar $\mathrm{KI}$ in the presence of a stimulus that elevates intracellular calcium concentration [20]. Purinergic receptor stimulation is known to mobilize intracellular calcium in FRTL-5 cells [6,33,34], and in other cell types activates ANO1 [20,22]. The substitution of $\mathrm{Na}^{+}$with $\mathrm{K}^{+}$clamps the membrane potential close to zero and serves to maximize ANO1 activity by enhancing the intrinsic $\mathrm{Ca}^{2+}$-sensitivity of ANO1, and by preventing the hyperpolarization that may arise from $\mathrm{Ca}^{2+}$-dependent $\mathrm{K}^{+}$channels [20]. $\mathrm{NaCl} / \mathrm{KI}$ substitution resulted in a slow quenching of FRTL-5/YFP fluorescence $(20 \%$ 


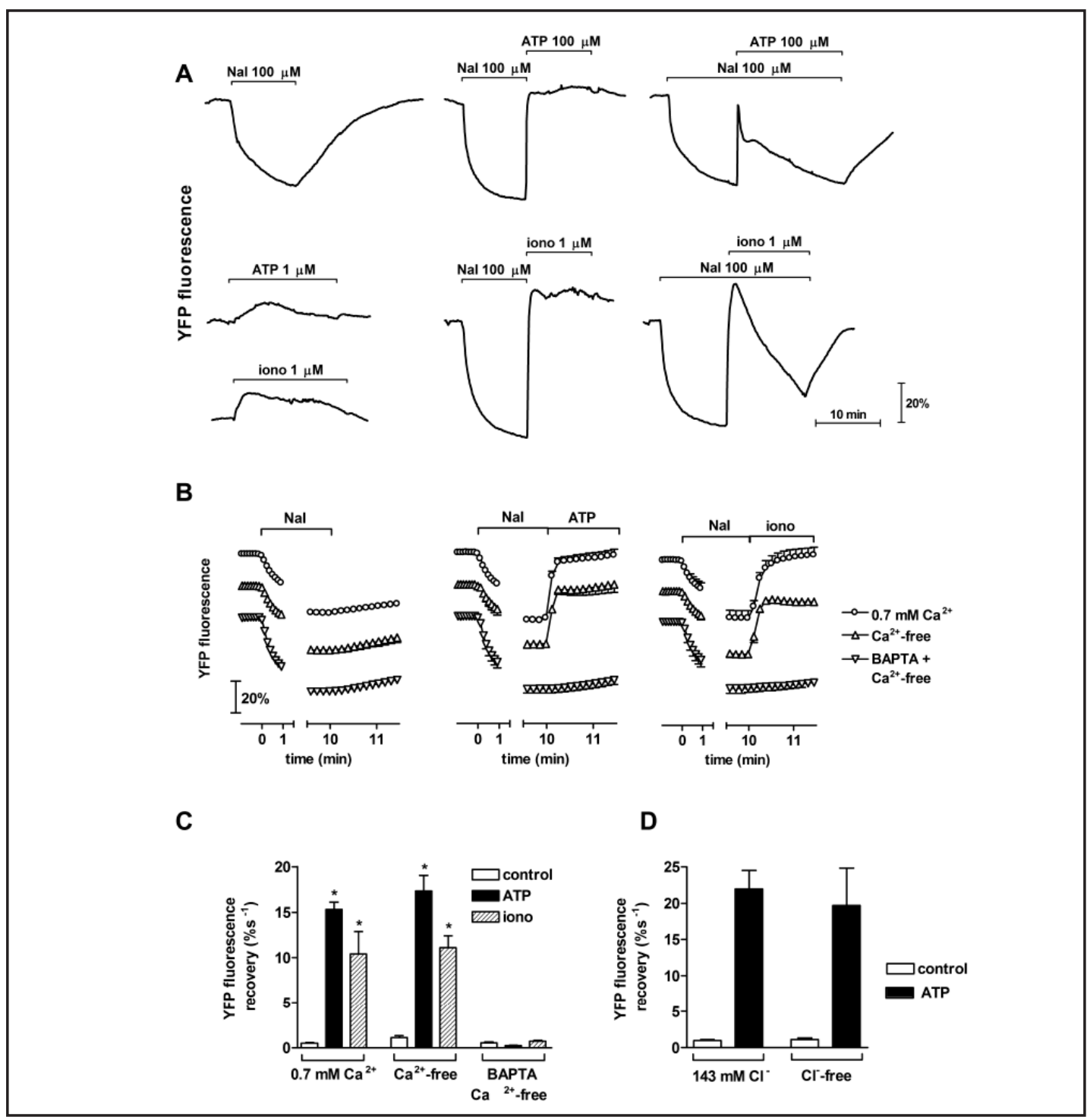

Fig. 4. Stimulation of iodide efflux from FRTL-5/YFP cells by ATP and ionomycin. (A) Representative tracings of fluorescence changes induced by $\mathrm{NaI}(100 \mu \mathrm{M})$, ATP $(100 \mu \mathrm{M})$ and ionomycin $(1 \mu \mathrm{M})$. NaI causes a reversible decrease in fluorescence due to iodide uptake and subsequent efflux. Exposure of iodide-containing cells to ATP or ionomycin causes a rapid recovery of resting fluorescence within 30s, which in the continued presence of extracellular iodide is transient. ATP and ionomycin individually increase resting fluorescence by $10-15 \%$. (B) Time-course and calcium-dependence of ATP- and ionomycin-induced iodide efflux. Cells were loaded with iodide by perfusing cells with $100 \mu \mathrm{M} \mathrm{NaI}$ for $10 \mathrm{~min}$ (image acquisition was paused during this phase in order to avoid photo-bleaching), and then exposed to iodide-free medium containing 100 $\mu \mathrm{M}$ ATP or $1 \mu \mathrm{M}$ ionomycin (iono) to stimulate iodide efflux. Experiments were carried out in the presence of $0.7 \mathrm{mM} \mathrm{Ca}^{2+}$ (left panel), $\mathrm{Ca}^{2+}$-free medium (central panel), or $\mathrm{Ca}^{2+}$-free medium in cells pre-treated with $10 \mu \mathrm{M}$ BAPTA-AM for $45 \mathrm{~min}$ (right panel). (C) Calcium-dependence of ATP- and ionomycin-stimulated iodide efflux, expressed as the maximal rate of fluorescence recovery derived from time course data in (B). * $\mathrm{p}<0.001$ vs. control in each treatment group. (D) Effect of extracellular chloride on ATP-stimulated iodide efflux, expressed as the maximal rate of fluorescence recovery. Symbols and bars in panels B-D represent mean \pm SEM of $n=4-8$ independent experiments.

within 20s) that was dramatically enhanced by both ATP and ionomycin (80\% within 20s) (Fig. 2 and 3A). Fluorescence quenching induced by both stimuli was abolished by chelating intracellular and extracellular calcium $\left(\mathrm{Ca}^{2+}\right.$-free medium + BAPTA) confirming 
A

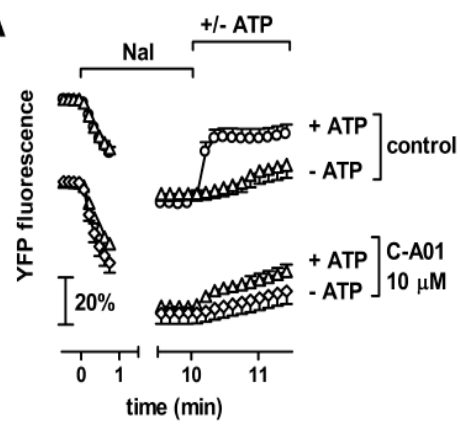

C

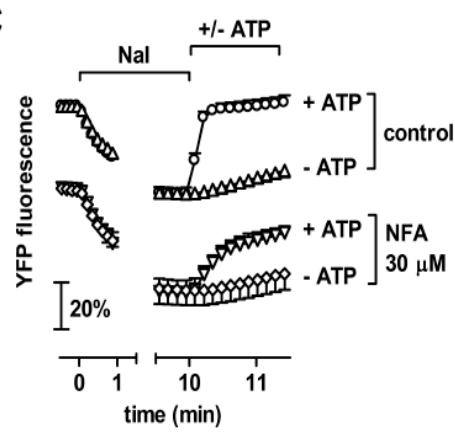

B

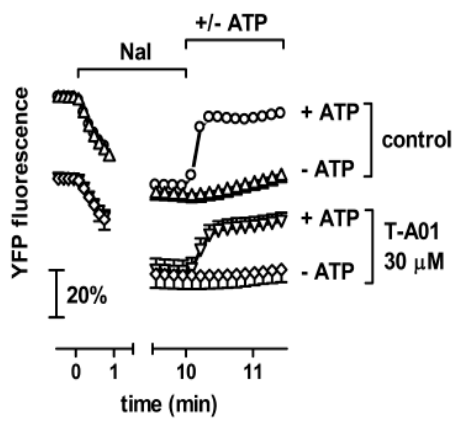

D

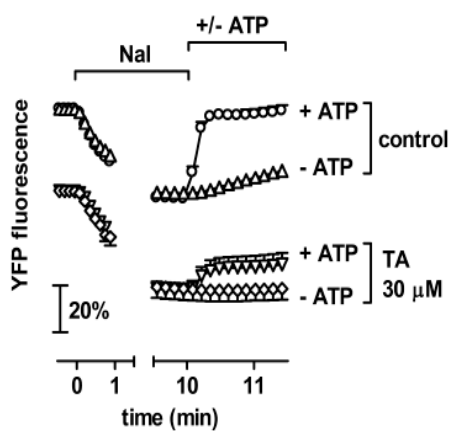

E

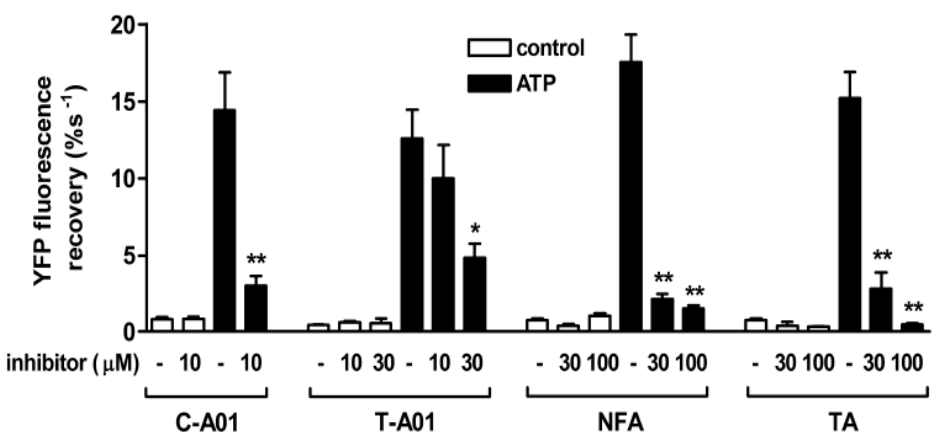

Fig. 5. Effect of CaCC/ANO1 inhibitors on ATP-stimulated iodide efflux from FRTL-5/YFP cells. Cells were loaded with iodide by perfusing cells with $100 \mu \mathrm{M} \mathrm{NaI}$ for $10 \mathrm{~min}$, and then exposed to iodide-free medium containing $100 \mu \mathrm{M}$ ATP to stimulate iodide efflux. Inhibitors were added to the perfusate 2 min before NaI, and were present throughout the experiment. Panels A-D show the time course of fluorescence changes in cells treated with (A) CaCCinh-A01 (C-A01), (B) T16Ainh-A01 (T-A01), (C) niflumic acid (NFA), or (D) tannic acid (TA). Panel E shows the maximal rate of fluorescence recovery calculated from time course data. ${ }^{*} \mathrm{p}<0.01,{ }^{* *} \mathrm{p}<0.001$ vs ATP, no inhibitor. Symbols and bars represent mean \pm SEM of $n=4-9$ independent experiments.

the calcium-dependence of halide fluxes (Fig. 3A and 3B). Removing only extracellular calcium had no effect, suggesting that halide fluxes are dependent on the mobilization of calcium from intracellular stores. Fluorescence quenching was enhanced by P2Y purinergic receptor agonists, with potencies of $0.95 \mu \mathrm{M}$ for ATP $\left(\mathrm{EC}_{50}=-6.02 \pm 0.06, \mathrm{n}=9\right), 1.5 \mu \mathrm{M}$ for UTP $\left(\mathrm{EC}_{50}=-5.82 \pm 0.10, \mathrm{n}=5\right)$ and $13 \mu \mathrm{M}$ for $\mathrm{ADP}\left(\mathrm{EC}_{50}=-4.88 \pm 0.09, \mathrm{n}=5\right)$ (Fig. $\left.3 \mathrm{C}\right)$. Hill coefficients for all three nucleotides were greater than 1 (2.1 for ATP, and 2.7 for both UTP and ADP) suggesting cooperativity. Substituting $\mathrm{NaCl}$ with equimolar NaI rather than KI decreased ATP's potency 10 -fold to $11 \mu \mathrm{M}\left(\mathrm{EC}_{50}=-4.98 \pm 0.25, \mathrm{n}=4\right)$, and reduced the Hill coefficient to 0.8 (Fig. 3C), consistent with the voltage dependence of CaCC activity. ATP-stimulated fluorescence quenching was inhibited by CaCC/ANO1 blockers including CaCCinh-A01 (10 
A

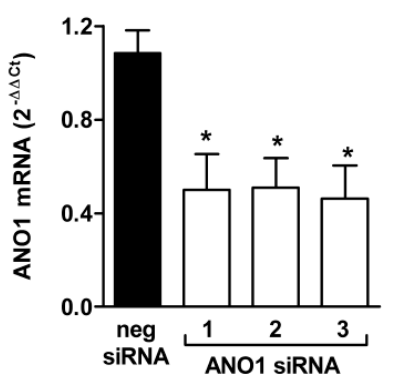

C

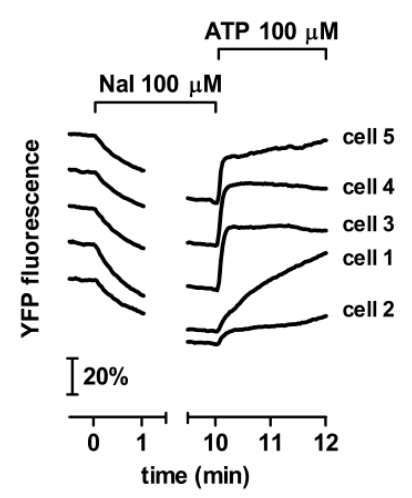

B
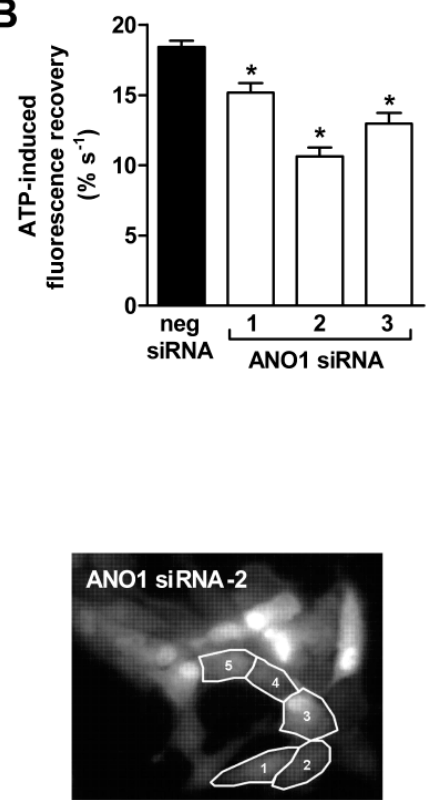

Fig. 6. Effect of RNA interference on ANO1 expression and ATP-stimulated iodide efflux in FRTL-5/YFP cells. Cells were treated with three different siRNA against rat ANO1 (ANO1 siRNA 1-3) or a scrambled siRNA as a negative control (neg siRNA). (A) AN01 mRNA levels measured by quantitative RT-PCR, normalized against $\beta$-actin and expressed relative to untreated cells by the $2^{-\Delta \Delta C t}$ method. Bars represent mean \pm SEM of 4 independent experiments, each in duplicate. ${ }^{*} \mathrm{p}<0.05$ vs. neg siRNA. (B) Maximal rate of fluorescence recovery induced by ATP. Cells were loaded with iodide by $10 \mathrm{~min}$ exposure to $100 \mu \mathrm{M} \mathrm{NaI}$, and were then exposed to $100 \mu \mathrm{M}$ ATP in iodide-free medium to stimulate efflux. Bars represent mean+SEM of measurements on 120-160 individual cells from 4 independent experiments for each siRNA. ${ }^{*} \mathrm{p}<0.01$ vs neg siRNA. (D) Heterogeneity of ATP-stimulated iodide efflux in FRTL-5/YFP cells treated with AN01 siRNA-2. Fluorescence changes are shown for 5 individual cells (cells 1-5 right hand panel) exhibiting slow iodide efflux (cells 1 and 2) or rapid efflux (cells 3-5).

$\mu \mathrm{M})$, T16Ainh-A01 (30 $\mu \mathrm{M})$, niflumic acid (30 $\mu \mathrm{M})$ and tannic acid (100 $\mu \mathrm{M})$ (Fig. 3D), but was unaffected by the respective vehicle(s). T16Ainh-A01 and niflumic acid on their own reduced resting fluorescence by up to $15 \%$.

Calcium-activated iodide efflux from FRTL-5 cells

To determine whether CaCC/ANO1 contributes to iodide efflux from thyroid cells, FRTL-5/YFP cells expressing NIS were first loaded with iodide by exposing them to 100 $\mu \mathrm{M} \mathrm{NaI}$ for $10 \mathrm{~min}$, and were then stimulated with ATP or ionomycin to stimulate efflux. We have previously demonstrated that FRTL-5/YFP cells cultured in the presence of TSH, respond to $100 \mu \mathrm{M} \mathrm{NaI}$ with a perchlorate-sensitive decrease in YFP fluorescence due to NIS-mediated iodide uptake [31]. Rinsing iodide-loaded cells with iodide-free BSS results in a slow recovery of resting fluorescence due to iodide efflux, complete within 15-20 min (Fig. 4A). In contrast, rinsing cells with iodide-free BSS containing $100 \mu \mathrm{M}$ ATP or $1 \mu \mathrm{M}$ ionomycin causes fluorescence to return to resting levels within 30 seconds suggesting that these agents induce a rapid and complete loss of measurable intracellular iodide (Fig. 4A). Stimulation of cells with ATP or ionomycin in the continued presence of extracellular iodide causes a short-lived fluorescence recovery (Fig. 4A), suggesting that activation of iodide 
A. CHO/YFP/NIS

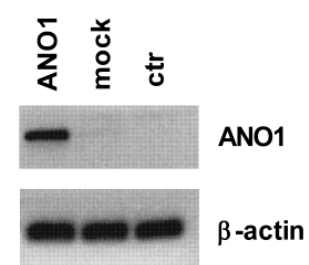

C. CHO/YFP/NIS mock

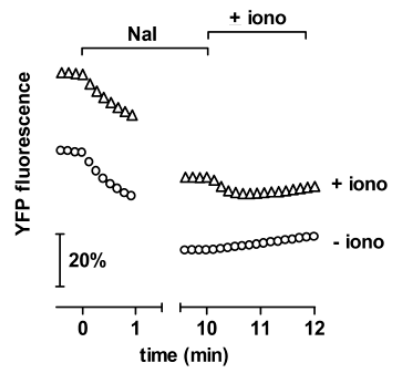

B. CHO/YFP/NIS

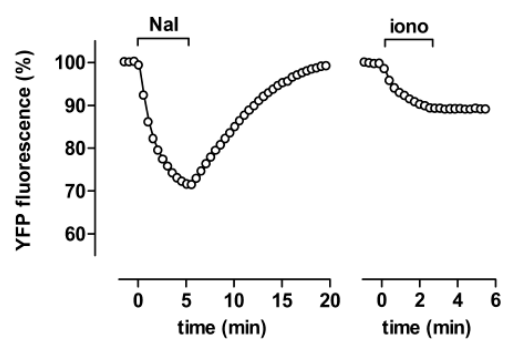

D. CHO/YFP/NISIANO1

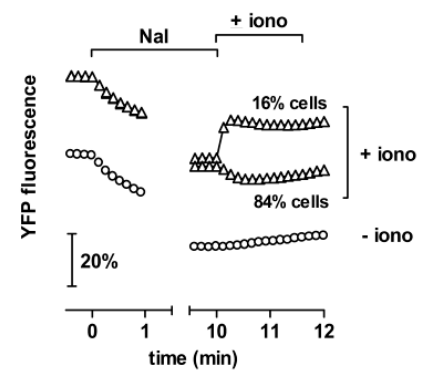

Fig. 7. Induction of calcium-activated iodide efflux in CHO cells expressing ANO1. ANO1 cDNA was transiently expressed in cells with stable NIS and YFP-H148/I152L expression (CHO/YFP/NIS). (A) ANO1 mRNA in control untreated CHO/YFP/NIS cells, and in cells transfected with ANO1 cDNA or mock empty vector. (B) Effect of $100 \mu \mathrm{M} \mathrm{NaI}$ and $1 \mu \mathrm{M}$ ionomycin (iono) on resting fluorescence of CHO/YFP/NIS cells (NaI $n=12$, ionomycin $n=4)$. (C) Effect of $1 \mu \mathrm{M}$ ionomycin on fluorescence recovery of iodide-containing CHO/YFP/NIS cells treated with mock vector (-iono, $n=210$ cells from 7 transfections +iono, $n=234$ cells from 9 transfections). (D) Effect of $1 \mu \mathrm{M}$ ionomycin on fluorescence recovery on iodide-containing $\mathrm{CHO} /$ YFP/NIS cells transfected with AN01 cDNA (-iono, $n=214$ cells from 9 transfections; +iono, $\mathrm{n}=488$ cells from 19 transfections). Data points represent mean \pm SEM.

efflux by ATP and ionomycin is transient, and that iodide is subsequently re-accumulated by cells via NIS. Both ATP and ionomycin cause small (10-15\%) transient increases in resting fluorescence. ATP- and ionomycin-induced fluorescence recovery was abolished by chelating intracellular and extracellular calcium, but was unchanged by removing only extracellular calcium, demonstrating the dependence of iodide efflux on the mobilization of calcium from intracellular stores (Fig. 4B and 4C). ATP-stimulated fluorescence recovery was independent of extracellular chloride (Fig. 4D), but was inhibited by CaCC/ANO1 blockers including CaCCinh-A01 $(10 \mu \mathrm{M})$, T16Ainh-A01 $(30 \mu \mathrm{M})$, niflumic acid $(30 \mu \mathrm{M})$ and tannic acid $(30 \mu \mathrm{M})$ (Fig. 5).

The role of ANO1 in ATP-induced iodide efflux in thyroid cells was assessed by silencing ANO1 expression in FRTL-5/YFP cells with three different siRNAs directed against rat ANO1 (rANO1 siRNA-1, -2 and -3). Knockdown efficiency was assessed by RT-PCR, and found to be approximately $50 \%$ compared to a scrambled siRNA negative control $(\mathrm{p}<0.01$, one-way ANOVA) (Fig. 6A). ATP-stimulated fluorescence recovery was significantly reduced in cells treated with each of the three rAN01 siRNAs compared to cells treated with scrambled siRNA ( $\mathrm{p}<0.001$, one-way ANOVA) (Fig. 6B). Examination of fluorescence changes in individual cells following rANO1 siRNA treatment revealed a mixed population of cells with either slow or rapid fluorescence recovery in response to ATP, despite comparable levels of iodide-induced quenching (Fig. 6C), suggesting an all-or-none silencing of calcium-activated iodide efflux in a small number of individual cells within the population. 


\section{Iodide efflux from NIS- and ANO1-expressing CHO cells}

To confirm that ANO1 is capable of mediating calcium-activated iodide efflux, human ANO1 was transiently expressed in a CHO cell line with stable expression of NIS and YFP (CHO/YFP/NIS). RT-PCR analysis confirmed the presence of ANO1 mRNA in CHO/YFP/NIS cells transfected with AN01 cDNA, but not in cells transfected with empty vector (mock) or in untreated cells (control) (Fig. 7A). CHO/YFP/NIS cells respond to iodide (100 $\mu \mathrm{M} \mathrm{NaI)} \mathrm{with}$ a reversible decrease in fluorescence consistent with NIS-mediated uptake, similar, though smaller in magnitude, to that of FRTL-5/YFP cells (Fig. 7B). Iodide-induced fluorescence quenching was similar in cells transfected with ANO1 or empty vector, suggesting that iodide uptake is not affected by ANO1 expression. In CHO/YFP/NIS cells, fluorescence recovery in iodide-free buffer occurred slowly over a $15 \mathrm{~min}$ period (Fig. 7B), and was not stimulated by ionomycin (Fig. 7C) confirming that $\mathrm{CHO}$ cells do not have endogenous calcium-activated fluxes detectable with the YFP assay. Ionomycin actually provoked a further decrease in cellular fluorescence; however, a similar effect was seen on resting fluorescence in the absence of iodide (Fig. 7B) suggesting that it is independent of iodide transport. Addition of ionomycin to ANO-1 transfected CHO/YFP/NIS cells revealed two distinct populations: $16 \%$ of cells (79/488 cells from 19 independent transfections) exhibited a rapid but partial recovery of resting fluorescence consistent with calcium-stimulated iodide efflux; $84 \%$ cells (409/488 cells) showed a small decrease similar to that seen in cells lacking ANO1 (Fig. 7D), suggesting that ANO1 may be functional in only a fraction of cells, possibly due to low transfection efficiency or poor membrane targeting in these cells. Ionomycin-induced fluorescence recovery in CHO cells expressing ANO1 was smaller that seen in FRTL-5 cells, however, it was probably underestimated because of the opposing effect of ionomycin on resting fluorescence.

\section{Discussion}

The results of the present study support the hypothesis that ANO1 contributes to iodide fluxes in the thyroid gland. In human tissues, AN01 protein was restricted to the apical membrane of follicular cells, and is therefore ideally located to mediate ion exchange between the cellular and follicular compartments. ANO1 was not uniformly detected in all follicles, but was more evident in those with columnar cells rather than low cuboidal cells, suggesting that its expression may be regulated according to the functional status of follicles. A similar pattern has been described for pendrin, and is in line with the well-known functional and morphological heterogeneity between follicles that characterizes the thyroid gland [35]. TSH does not appear to be essential for ANO1 gene transcription in FRTL-5 cells, but it remains to be determined whether TSH may exert a modulatory effect on ANO1 expression at a transcriptional or post-transcriptional level.

CaCC activity has previously been identified in thyroid cells. Patch-clamp studies have revealed $\mathrm{Ca}^{2+}$-activated $\mathrm{Cl}^{-}$currents in FRTL- 5 cells that are stimulated by ATP, and by calcium influx through transient receptor potential channels (TRPCs) [27, 28]. Using the YFP-based assay, we detected CaCC activity in FRTL-5 cells compatible with ANO1 function. CaCC activity was stimulated by purinergic receptor agonists through mobilization of $\mathrm{Ca}^{2+}$ from intracellular stores. In nociceptive sensory neurons, ANO1 is present in plasma membrane lipid rafts in close apposition to the endoplasmic reticulum, and is preferentially activated by localized rather than by global changes in intracellular calcium concentration. [36]. Depolarization increased the potency of ATP in FRTL-5 cells. This is unlikely to reflect increased calcium mobilization, since depolarization has been shown not to change ATPinduced $\mathrm{Ca}^{2+}$ release from intracellular stores in these cells [37]. A more likely explanation lies in the voltage-dependence of ANO1 which manifests an increased calcium-sensitivity as the membrane potential is shifted from negative to positive values [22, 25]. Hill coefficients for purinergic agonists in a depolarizing medium were $>1$ suggesting cooperativity. The calciumsensitivity of ANO1 is also characterized by cooperativity, possibly due to calcium binding 
at multiple sites. The mechanism by which calcium activates and modulates ANO1 appear to be complex, involving calmodulin as well as direct binding to AN01 [23]. AN01 splice variants differ in their calcium-sensitivity, the $(a c)$ isoform having a significantly higher $\mathrm{Ca}^{2+}$ sensitivity than the $(a b c)$ isoform [25]. Both $(a c)$ and $(a b c)$ isoforms are present in FRTL5 cells, but the significance is unclear. ATP-stimulated fluorescence quenching in FRTL-5 cells was inhibited by known AN01/CaCC blockers, most notably by CaCCinh-A01, and to a lesser degree by T16Ainh-A01, niflumic acid and tannic acid, albeit at high concentrations. All four compounds inhibit calcium-activated chloride currents in cells with heterologous and endogenous ANO1 expression [21, 22, 38-41], although niflumic acid and tannic acid are not selective. The pharmacological sensitivity of ANO1 may vary according to cell type and the ionic environment of the channel. The inhibition of ANO1 by niflumic acid, for instance, is antagonized by the occupancy of anions in the pore, and is less effective in the presence of iodide versus chloride [41].

The apical localization of ANO1 on thyroid follicular cells and its higher permeability for iodide than for chloride raises the possibility that ANO1 may mediate calcium-activated iodide efflux from thyroid cells. Indeed, ATP and ionomycin induced a rapid and complete loss of iodide from pre-loaded FRTL-5 cells, secondary to calcium release from intracellular stores. ATP and calcium ionophores have previously been shown to stimulate radioiodide efflux from FRTL-5 cells [4-6, 8], although in one study the effect of ATP was reported to be independent of calcium mobilization [8]. In the present study, calcium-activated iodide efflux was rapid and transient, allowing iodide to be subsequently re-accumulated via NIS. This may reflect the transient nature of calcium mobilization or may be due to inactivation of the iodide-permeable channel. ANO1 currents are also transient, and following opening, AN01 channels are inactivated in the continued presence of elevated calcium, possibly via calmodulin-dependent kinase [42]. AN01/CaCC blockers also inhibited calcium-activated iodide efflux from FRTL-5 cells, CaCCinh-A01 showing the greatest effect. Notably, niflumic acid and tannic acid were more effective against iodide efflux than influx. In the case of niflumic acid this could be explained by the reduced anion occupancy of the AN01 pore in the presence of the lower concentration of iodide used in efflux studies. However, niflumic acid and tannic acid are known to have a broad spectrum of activity, and may therefore inhibit additional pathways of iodide efflux. ATP-induced iodide efflux from FRTL-5 cells was also inhibited by three ANO1-specific siRNAs, however, knockdown of ANO1 gene expression was only partial, and we cannot exclude the involvement of other calcium-sensitive pathways in addition to ANO1.

The present study has technical drawbacks. The first lies in the high concentration of extracellular iodide $(100 \mu \mathrm{M})$ used to load cells for the measurement of iodide efflux. This concentration is considerably higher than the circulating iodide concentration in the human body $(<1 \mu \mathrm{M})$, and was necessary both to stimulate uptake by NIS (whose affinity for iodide is $\sim 30 \mu \mathrm{M}$ ) and to be detectable by YFP-H148Q/Y152L (whose affinity for iodide is $\sim 2 \mathrm{mM}$ ). Although measurement of iodide fluxes with radiotracers can be achieved with lower external iodide concentrations (typically $10 \mu \mathrm{M}$ ), the rapid and transient nature of AN01 activation would be poorly detected with radioiodide. The second drawback lies in the use of FRTL-5 cells which, although highly functional, are not polarized and do not support the vectorial transport that occurs in the intact thyroid gland in vivo. The ability of ANO1 to mediate calcium-dependent iodide efflux was confirmed in CHO cells with heterologous expression of NIS and ANO1, however, further studies with polarized thyroid cells will be necessary to confirm apical iodide efflux by ANO1.

Could other anoctamins contribute to calcium-activated iodide fluxes in thyroid cells? In addition to AN01, FRTL-5 thyrocytes express mRNA for ANO6 (TMEM16F), ANO8 (TMEM16H), and ANO10 (TMEM16K), confirming and extending Viitanen et al.'s finding of ANO1 and ANO10 in these cells [27]. ANO6 contributes to calcium-dependent phospholipid scrambling in platelets and is an essential component of the outwardly rectifying chloride channels (ORCC) [43, 44]. Over-expressed ANO6, ANO8 and ANO10 possess a variable CaCC activity, but with a lower calcium sensitivity and magnitude than ANO1 [26, 42]. FRT 
cells, which like FRTL- 5 cells originate from Fischer rat thyroid follicular epithelium [30, 45], express AN06, ANO8 and AN010, but not AN01 [26]. These cells have no detectable CaCC activity and have been used as host cells to study CaCC activity following heterologous expression of anoctamins $[20,26]$. It is therefore highly unlikely that ANO6, ANO8 or ANO10 mediate CaCC activity in FRTL-5 cells. Since FRT cells are completely devoid of thyroidspecific protein expression and function [45], the differential expression of ANO1 between FRT and FRTL-5 cells is consistent with a link between ANO1 expression and the functional status of thyroid cells.

An important question is whether ANO1 acts directly as an iodide channel, or indirectly by modulating iodide fluxes through pendrin or other pathways. ClC- 5 and CFTR have both been proposed to supply chloride as the counter-ion for pendrin-mediated chloride/iodide exchange $[18,19]$. However, ATP was still able to stimulate iodide efflux from FRTL-5 cells in the absence of chloride suggesting independence of pendrin activity. Another contentious point concerns the the preferred direction of ANO1-mediated fluxes in vivo. ANO1 has a strong outward rectification, at least with respect to chloride currents [21, 22]. However, ANO1 rectification is regulated by $\mathrm{Ca}^{2+}$, and the channel could mediate anion secretion or absorption in epithelial cells, depending on the interplay of membrane potential, equilibrium potential, and intracellular $\mathrm{Ca}^{2+}$ [46]. ANO1 rectification is also dependent on the permeant anion. Replacement of chloride with $\mathrm{NO}_{3}^{-}$as the permeant anion reduces outward rectification, possibly reflecting the higher occupancy of the pore due to the lower hydration energy of $\mathrm{NO}_{3}^{-}$[46]. The same may be true of iodide which, like $\mathrm{NO}_{3}{ }^{-}$, has a lower hydration energy and a higher relative permeability towards ANO1 than chloride. In thyroid cells, NIS maintains a large outward electrochemical gradient for iodide providing a strong driving force for iodide efflux.

The results of this study suggest that ANO1 may be a novel pathway for the delivery of iodide into the follicular lumen for incorporation into thyroglobulin. Further studies are needed to confirm this role using more physiological thyroid models and iodide concentrations. Iodide efflux through pendrin may be sufficient to maintain basal thyroid hormone synthesis, but the activation of ANO1 may provide an acute supply of iodide under conditions of thyroid stimulation by calcium mobilizing agents. Although ATP is a ubiquitous extracellular messenger that is secreted by many cell types, particularly during inflammation, the physiological stimuli for ANO1 activation in the thyroid gland in vivo remain to be determined. In addition to supplying iodide for thyroid hormone synthesis, ANO1 may also facilitate chloride fluxes, necessary for the coordinated regulation of colloid composition and follicle volume. The identification of ANO1 as a pathway of iodide transport opens up new lines of investigation regarding its regulation and function under pathophysiological conditions, and its potential as a pharmacological target for the treatment of thyroid disease.

\section{Acknowledgements}

This work was supported by grants from the Italian Ministry of Education, Universities and Research (PRIN award), the University of Bologna (Ricerca Fondamentale Orientata ex $60 \%$ ) and the Emilia-Romagna Region (POR-FESR).

\section{References}

1 Dohán O, De la Vieja A, Paroder V, Riedel C, Artani M, Reed M, Ginter CS, Carrasco N: The sodium/iodide symporter (NIS): Characterization, regulation, and medical significance. Endocr Rev 2003;24:48-77.

2 Weiss SJ, Philp NJ, Grollman EF: Effect of thyrotropin on iodide efflux in FRTL-5 cells mediated by $\mathrm{Ca}^{2+}$. Endocrinology 1984;114:1108-1113.

3 Corda D, Marcocci C, Kohn LD, Axelrod J, Luini A: Association of the changes in cytosolic $\mathrm{Ca}^{2+}$ and iodide efflux induced by thyrotropin and by the stimulation of alpha 1-adrenergic receptors in cultured rat thyroid cells. J Biol Chem 1985;260:9230-9236. 
Iosco et al.: Anoctamin 1 in the Thyroid Gland

4 Bidey SP, Tomlinson S: Differential modulation by $\mathrm{Ca}^{2+}$ of iodide transport processes in a cultured rat thyroid cell strain. J Endocrinol 1987;112:51-56.

5 Marcocci C, Luini A, Santisteban P, Grollman EF: Norepinephrine and thyrotropin stimulation of iodide efflux in FRTL-5 thyroid cells involves metabolites of arachidonic acid and is associated with the iodination of thyroglobulin. Endocrinology 1987;120:1127-1133.

-6 Okajima F, Sho K, Kondo Y: Inhibition by islet-activating protein, pertussis toxin, of P2-purinergic receptormediated iodide efflux and phosphoinositide turnover in FRTL-5 cells. Endocrinology 1988;123:10351043.

7 Nilsson M, Björkman U, Ekholm R, Ericson LE: Polarized efflux of iodide in porcine thyrocytes occurs via a cAMP-regulated iodide channel in the apical plasma membrane. Acta Endocrinol (Copenh) 1992;126:6774.

8 Smallridge RC, Gist ID: P2-purinergic stimulation of iodide efflux in FRTL-5 rat thyroid cells involves parallel activation of PLC and PLA2. Am J Physiol 1994;267:E323-330.

-9 Yoshida A, Hattori K, Hisatome I, Taniguchi S, Ueta Y, Hukui H, Santo Y, Igawa O, Shigemasa C, Kosugi S, Grollman EF: A TSH/dibutyryl camp activated $\mathrm{Cl}^{-} / \mathrm{I}^{-}$channel in FRTL-5 cells. Biochem Biophys Res Commun 1999;259:631-635.

10 Everett LA, Glaser B, Beck JC, Idol JR, Buchs A, Heyman M, Adawi F, Hazani E, Nassir E, Baxevanis AD, Sheffield VC, Green ED: Pendred syndrome is caused by mutations in a putative sulphate transporter gene (PDS). Nat Genet 1997;17:411-422.

11 Scott DA, Wang R, Kreman TM, Sheffield VC, Karniski LP: The Pendred syndrome gene encodes a chlorideiodide transport protein. Nat Genet 1999;21:440-443.

12 Royaux IE, Suzuki K, Mori A, Katoh R, Everett LA, Kohn LD, Green ED: Pendrin, the protein encoded by the Pendred syndrome gene (PDS), is an apical porter of iodide in the thyroid and is regulated by thyroglobulin in FRTL-5 cells. Endocrinology 2000;141:839-845.

13 Gillam MP, Sidhaye AR, Lee EJ, Rutishauser J, Stephan CW, Kopp P: Functional characterization of pendrin in a polarized cell system. Evidence for pendrin-mediated apical iodide efflux. J Biol Chem 2004;279:1300413010

14 Everett LA, Belyantseva IA, Noben-Trauth K, Cantos R, Chen A, Thakkar SI, Hoogstraten-Miller SL, Kachar B, Wu DK, Green ED: Targeted disruption of mouse Pds provides insight about the inner-ear defects encountered in Pendred syndrome. Hum Mol Genet 2001; 10:153-161

15 Taylor JP, Metcalfe RA, Watson PF, Weetman AP, Trembath RC: Mutations of the PDS gene, encoding pendrin, are associated with protein mislocalization and loss of iodide efflux: implications for thyroid dysfunction in Pendred syndrome. J Clin Endocrinol Metab 2002;87:1778-17784

16 Devuyst O, Golstein PE, Sanches MV, Piontek K, Wilson PD, Guggino WB, Dumont JE, Beauwens R: Expression of CFTR in human and bovine thyroid epithelium. Am J Physiol 1997;272:C1299-1308.

17 De Luca F, Trimarchi F, Sferlazzas C, Benvenga S, Costante G, Mami C, Di Pasquale G, Magazzu G: Thyroid function in children with cystic fibrosis. Eur J Pediatr 1982;138:327-330.

-18 Li H, Ganta S, Fong P: Altered ion transport by thyroid epithelia from CFTR(-/-) pigs suggests mechanisms for hypothyroidism in cystic fibrosis. Exp Physiol 2010;95:1132-1144.

19 van den Hove MF, Croizet-Berger K, Jouret F, Guggino SE, Guggino WB, Devuyst O, Courtoy PJ: The loss of the chloride channel, ClC-5, delays apical iodide efflux and induces a euthyroid goiter in the mouse thyroid gland. Endocrinology 2006;147:1287-1296

20 Caputo A, Caci E, Ferrera L, Pedemonte N, Barsanti C, Sondo E, Pfeffer U, Ravazzolo R, Zegarra-Moran O, Galietta LJ: TMEM16A, a membrane protein associated with calcium-dependent chloride channel activity. Science 2008;322:590-594.

21 Schroeder BC, Cheng T, Jan YN, Jan LY: Expression cloning of TMEM16A as a calcium-activated chloride channel subunit. Cell 2008;134:1019-1029.

22 Yang YD, Cho H, Koo JY, Tak MH, Cho Y, Shim WS, Park SP, Lee J, Lee B, Kim BM, Raouf R, Shin YK, Oh U: TMEM16A confers receptor-activated calcium-dependent chloride conductance. Nature 2008;455:12101215.

23 Pedemonte N, Galietta LJ: Structure and function of TMEM16 proteins (anoctamins). Physiol Rev 2014;94:419-459.

24 Rock JR, Harfe BD: Expression of TMEM16 paralogs during murine embryogenesis. Dev Dyn 2008;237:2566-2574. 
Iosco et al.: Anoctamin 1 in the Thyroid Gland

25 Ferrera L, Caputo A, Ubby I, Bussani E, Zegarra-Moran O, Ravazzolo R, Pagani F, Galietta LJ: Regulation of TMEM16A chloride channel properties by alternative splicing. J Biol Chem 2009;284:33360-33368.

-26 Schreiber R, Uliyakina I, Kongsuphol P, Warth R, Mirza M, Martins JR, Kunzelmann K: Expression and function of epithelial anoctamins. J Biol Chem 2010;285:7838-7845.

27 Viitanen TM, Sukumaran P, Löf C, Törnquist K: Functional coupling of TRPC2 cation channels and the calcium-activated anion channels in rat thyroid cells: Implications for iodide homeostasis. J Cell Physiol 2013;228:814-823.

28 Martin SC: ATP activates a $\mathrm{Ca}^{2+}$-dependent $\mathrm{Cl}^{-}$current in the rat thyroid cell line, FRTL-5. J Membr Biol 1992;125:243-253.

29 West RB, Corless CL, Chen X, Rubin BP, Subramanian S, Montgomery K, Zhu S, Ball CA, Nielsen TO, Patel R, Goldblum JR, Brown PO, Heinrich MC, van de Rijn M: The novel marker, DOG1, is expressed ubiquitously in gastrointestinal stromal tumors irrespective of kit or PDGFRA mutation status. Am J Pathol 2004;165:107113.

-30 Ambesi-Impiombato FS, Parks LA, Coon HG: Culture of hormone-dependent functional epithelial cells from rat thyroids. Proc Natl Acad Sci U S A 1980;77:3455-3459.

-31 Rhoden KJ, Cianchetta S, Stivani V, Portulano C, Galietta LJ, Romeo G: Cell-based imaging of sodium iodide symporter activity with the yellow fluorescent protein variant H148Q/I152L. Am J Physiol Cell Physiol 2007;292:C814-823.

32 Manoury B, Tamuleviciute A, Tammaro P: TMEM16A/anoctamin 1 protein mediates calcium-activated chloride currents in pulmonary arterial smooth muscle cells. J Physiol 2010;588:2305-2314.

33 Törnquist K: Calcium fluxes in rat thyroid FRTL-5 cells. Evidence for $\mathrm{Ca}^{2+}$ entry after stimulation with ATP. Mol Cell Endocrinol 1991;79:147-156.

34 Bizzarri C, Corda D: Norepinephrine, unlike ATP, induces all-or-none increase in cytosolic calcium in thyroid cells. The role of inositol-trisphosphate-sensitive stores and calcium channels. Eur J Biochem 1994;219:837-844.

-35 Gérard AC, Many MC, Daumerie C, Costagliola S, Miot F, DeVijlder JJ, Colin IM, Denef JF: Structural changes in the angiofollicular units between active and hypofunctioning follicles align with differences in the epithelial expression of newly discovered proteins involved in iodine transport and organification. J Clin Endocrinol Metab 2002;87:1291-1299.

-36 Jin X, Shah S, Liu Y, Zhang H, Lees M, Fu Z, Lippiat JD, Beech DJ, Sivaprasadarao A, Baldwin SA, Gamper N: Activation of the $\mathrm{Cl}^{-}$channel ANO1 by localized calcium signals in nociceptive sensory neurons requires coupling with the IP3 receptor. Sci Signal 2013;6:ra73.

-37 Törnquist K: Depolarization of the membrane potential decreases the ATP-induced influx of extracellular $\mathrm{Ca}^{2+}$ and the refilling of intracellular $\mathrm{Ca}^{2+}$ stores in rat thyroid FRTL-5 cells. J Cell Physiol 1991;149:485491.

-38 De La Fuente R, Namkung W, Mills A, Verkman AS: Small-molecule screen identifies inhibitors of a human intestinal calcium-activated chloride channel. Mol Pharmacol 2008;73:758-768.

39 Namkung W, Thiagarajah JR, Phuan PW, Verkman AS: Inhibition of $\mathrm{Ca}^{2+}$-activated $\mathrm{Cl}^{-}$channels by gallotannins as a possible molecular basis for health benefits of red wine and green tea. FASEB J 2010;24:4178-4186.

40 Namkung W, Phuan PW, Verkman AS: TMEM16A inhibitors reveal TMEM16A as a minor component of calcium-activated chloride channel conductance in airway and intestinal epithelial cells. J Biol Chem 2011;286:2365-2374.

41 Ni YL, Kuan AS, Chen TY: Activation and inhibition of TMEM16A calcium-activated chloride channels. PLoS One 2014;9:e86734.

42 Tian Y, Schreiber R, Kunzelmann K: Anoctamins are a family of $\mathrm{Ca}^{2+}$-activated $\mathrm{Cl}^{-}$channels. J Cell Sci 2012;125:4991-4998.

43 Suzuki J, Umeda M, Sims PJ, Nagata S: Calcium-dependent phospholipid scrambling by TMEM16F. Nature 2010;468:834-838.

44 Martins JR, Faria D, Kongsuphol P, Reisch B, Schreiber R, Kunzelmann K: Anoctamin 6 is an essential component of the outwardly rectifying chloride channel. Proc Natl Acad Sci USA 2011;108:18168-18172.

45 Ambesi-Impiombato FS, Coon HG: Thyroid cells in culture. Int Rev Cytol Suppl 1979:163-172.

46 Xiao Q Yu K, Perez-Cornejo P, Cui Y, Arreola J, Hartzell HC. Voltage- and calcium-dependent gating of TMEM16A/Ano1 chloride channels are physically coupled by the first intracellular loop. Proc Natl Acad Sci USA 2011;108:8891-8896. 